\title{
Generation of tumor-reactive effector lymphocytes using tumor RNA-introduced dendritic cells in gastric cancer patients
}

\author{
AKIKO OHSHITA, YOSHIYUKI YAMAGUCHI, KAZUHITO MINAMI, RIKI OKITA and TETSUYA TOGE \\ Department of Surgical Oncology, Research Institute for Radiation Biology and Medicine, \\ Hiroshima University, Kasumi 1-2-3, Minami-ku, Hiroshima 734-8553, Japan
}

Received November 15, 2005; Accepted December 28, 2005

\begin{abstract}
Anti-tumor effector cells were generated by stimulating peripheral blood lymphocytes with cultured dendritic cells (DCs) and mRNA extracted from the gastric cancer cell line MKN45 or ascites tumor cells of gastric cancer patients. DCs were generated from an adherent fraction of peripheral blood mononuclear cells (PBMCs) in the presence of GM-CSF and IL-4. mRNA was extracted from tumor cells and subjected to T7-amplification. The DCs were electroporated $(150 \mathrm{~V} / 150 \mu \mathrm{F})$ with amplified mRNA and used after maturation with TNF- $\alpha$ to stimulate PBMCs to generate tumor RNA-introduced DC-activated killer (TRiDAK) cells. It was found that tumor RNA could efficiently be introduced into cultured DCs by electroporation (55\% efficiency, 78\% viability), and tumor RNA-introduced DCs could reproducibly stimulate lymphocytes to be tumor-reactive TRiDAK cells. The TRiDAK cells expressed an IFN- $\gamma$ response specific for tumor cells, but not for normal cells. Mock DCs or normal cell
\end{abstract}

Correspondence to: Dr Yoshiyuki Yamaguchi, Department of Surgical Oncology, Research Institute for Radiation Biology and Medicine, Hiroshima University, Kasumi 1-2-3, Minami-ku, Hiroshima 734-8553, Japan

E-mail: shogo@hiroshima-u.ac.jp

Abbreviations: AK, activated killer; APCs, antigen presenting cells; CEA, carcinoembryonic antigen; $\mathrm{CD}$, cluster of differentiation; CTLs, cytotoxic T-cells; DCs, dendritic cells; DNA, deoxyribonucleotide; DMSO, dimethyl sulfoxide; EGFP, enhanced green fluorescence protein; ELISA, enzyme-linked immunosorbent assay; ELISPOT, enzyme-linked immunospot; FBS, fetal bovine serum; GM-CSF, granulocyte-macrophage colony stimulating factor; HLA, human leukocyte antigen; IFN, interferon; IL, interleukin; LAK, lymphokine-activated killer; MAGE, melanoma antigenencoding gene; mRNA, messenger ribonucleotide; MMC, mitomycin C; PDAK, peptide-pulsed dendritic cell-activated killer; PBMCs, peripheral blood mononuclear cells; PCR, polymerase chain reaction; RPMI, Roswell Park Memorial Institute; TCR, T cell receptor; TAAs, tumor-associated antigens; TILs, tumor-infiltrating lymphocytes; TNF, tumor necrosis factor; TRiDAK, tumor RNAintroduced dendritic cell-activated killer

Key words: dendritic cells, tumor mRNA, cytotoxic T cells, gastric cancer, TRiDAK cells
RNA-introduced DCs did not induce any killer cells. RNAspecific recognition of the effector cells generated was demonstrated using an amplified EGFP-mRNA system. The tumor killing activity of TRiDAK cells was inhibited not only with the anti-HLA class I antibody but also with the anti-HLA class II antibody as well as the anti-TCR antibody. TRiDAK cells reactive with autologous tumor cells could be generated in a CEA-positive gastric cancer patient with malignant ascites, in whom effector cell generation using DCs and CEA peptides had failed. These results suggest that TRiDAK cell generation is safe, feasible, and active in gastric cancer patients with malignant ascites, and is superior to other effector cell generation systems using DCs and epitope peptides. The adoptive immunotherapy of cancer using TRiDAK cells may be warranted in a clinical setting. This is the first study investigating anti-tumor effector cell generation using cultured DCs and tumor mRNA from gastric cancer cells.

\section{Introduction}

Gastric cancer is one of the most frequent malignancies worldwide, accounting for $10.4 \%$ of cancer deaths in 2000 (1). Although recent progress in the diagnosis of gastric cancer using endoscopy has enabled the detection of gastric tumors at relatively earlier stages, the prognosis of gastric cancer patients at an advanced stage still remains poor. The efficacies of other therapeutic modalities, such as chemotherapy, are limited; the overall 5-year survival rate of advanced tumors ranges from 5 to $15 \%$ (2). Hence, the development of novel therapeutic strategies is urgently needed for the treatment of patients with advanced gastric cancer.

Identification of the melanoma antigen-encoding gene (MAGE) by van der Bruggen et al (3) has contributed greatly to the molecular understanding of antigen presentation and recognition in the immune system (4). Many CTL epitopes have been reported as targets for gastric cancer; Her-2/neu (5), NY-ESO-1 and MAGE (6), immediate early response gene X-1 (7), immunoglobulin superfamily 11 (IGSF11) (8), and survivin (9). However, a clinical study of vaccine trials for patients with gastric cancer has still demonstrated unsatisfactory results (10). One possible reason for these poor clinical results may have to do with the heterogenic nature of gastric cancer antigens as well as many clinical tumors. To deal with the heterogeneity of clinical tumors, Chen et al (11) have indicated the necessity for multiple vaccine preparation. Mine et al (12) have demonstrated notable tumor responses 
in clinical trials only with CTL precursor-oriented multiple vaccines. These observations indicate that multiple epitopes should be targeted to augment the clinical responses of immunotherapy for patients with gastric cancer.

It has been shown that murine and human DCs transfected with tumor-derived mRNA can stimulate multi-specific potent CTL responses in vitro and in vivo (13-15). The use of the RNA form as a tumor-associated antigen has significant advantages since 1) tumor RNA may code multiple tumor antigens, 2) the antigens and HLA phenotypes must not be identified when educating naïve $\mathrm{T}$ cells to tumor specific CTLs, 3) it can be amplified in sufficient amounts from only a few tumor cells by polymerase chain reaction (16). We have been engaged in the adoptive immunotherapy of cancer using autologous activated lymphocytes including lymphokine-activated killer (LAK) cells, tumor-infiltrating lymphocytes (TILs), tumor-sensitized lymphocytes, and peptide-pulsed DC-activated killer (PDAK) cells $(8,17)$. The above studies encouraged us to use DCs introduced with tumor mRNA in order to advance the immunotherapeutic approaches using autologous activated lymphocytes. Here, we show the successful generation of effective autologous lymphocytes reactive with autologous tumors in gastric cancer patients with malignant ascites.

\section{Materials and methods}

Reagents. The reagents used in this study were: HLA-A2402 restricted synthetic peptides ( $>90 \%$ pure), including CEA10(10) (RWCIPWQRLL), CEA101(9) (IYPNASLLI), CEA234(9) (LYGPDAPTI), CEA268(10) (QYSWFVNGTF), CEA318(9) (VYAEPPKPF), CEA425(9) (TYYRPGVNL), CEA426(10) (YYRPGVNLSL), CEA590(9) (LYGPDTPII), CEA604(10) (SYLSGANLNL), CEA652(9) (TYACFVSNL), FLU38(10) (RFYIQMCTEL), (19,20), HER2 780 (PYVSRL LGI) (21) (Takara Bio Inc., Ohtsu, Japan); mouse monoclonal antibodies (mAbs) to human HLA-ABC (HLA-class I), HLADR (HLA-class II), and control Ig (Pharmingen, San Diego, CA, USA), CD4, CD8, CD25, TCR $\alpha$ ß (Becton Dickinson, San Diego, CA); interleukin (IL)-2 (Sionogi, Tokyo), IL-4, IL-7, granurocyte-macrophage colony stimulating factor (GMCSF), and TNF- $\alpha$ (IBL, Gunma, Japan).

Cancer cells and peripheral blood mononuclear cells. A human gastric cancer cell line MKN45 (HLA-A24) was purchased from the American Type Culture Collection and cultured in RPMI-1640 medium supplemented with $10 \%$ fetal bovine serum (FBS, Life Technologies, Paisely, UK). Peripheral blood mononuclear cells (PBMCs) and ascites cells were obtained by a Ficoll-Hypaque (Amersham Pharmacia Biotech, Piscataway, NJ) density gradient separation method (100\%, 75/ $100 \%$ ) at $800 \mathrm{~g}$ for $25 \mathrm{~min}$ from 3 healthy donors and 6 gastric cancer patients with malignant ascites after their written informed consent was obtained. PBMCs and ascites lymphocytes (tumor-infiltrating lymphocytes, TILs) were collected from a $100 \%$ interface, and ascites tumor cells from a $75 \%$ interface. The cells were washed 3 times with RPMI-1640 medium and subjected to further experiments. The tumor cells were frozen in fetal bovine serum supplemented with $10 \%$ DMSO until used as a target for the cytotoxicity assays.
RNA extraction, amplification, and in vitro transcription. Total RNA from MKN45, ascites tumor cells, or PBMCs was extracted using the RNeasy kit (Qiagen, Valencia, CA) according to the manufacturer's protocol. Total RNA was reverse transcribed using the Smart Race cDNA amplification kit (Clontech, CA, USA). Briefly, first strand full-length cDNA synthesis was primed with a modified oligo(dT) primer (5'-A AGCAGTGGTATCAACGCAGAGTAC (T) ${ }_{30} \mathrm{~N}_{-1}$ N-3', $\mathrm{N}=\mathrm{A}, \mathrm{C}, \mathrm{G}$, or $\mathrm{T} ; \mathrm{N}-1=\mathrm{A}, \mathrm{G}$, or $\mathrm{C}$ ) and a SMART II A Oligonucleotide (5'-AAGCAGTGGTATCAACGCAGATACGCG GG-3') and reverse-transcribed using Power Script reverse transcriptase for $1.5 \mathrm{~h}$ at $42^{\circ} \mathrm{C}$. For the full-length cDNA amplification, Universal primer mix A [Long; 5'-CTAATAC GACTCACTCACTATAGGGAAGCAGTGGTATCAACG CAGA-3', Short; 5'-CTAATACGACTCACTATAGGGC-3' (underline indicates $\mathrm{T} 7$ promoter sequence)], Nested Universal primer mix A (5'-AAGCAGTGGTATCAACGCAGAGT-3'), the Advantage DNA polymerase mix, and the following cycling parameters were used: $95^{\circ} \mathrm{C}$ for $60 \mathrm{sec} \times 1$ cycle, $95^{\circ} \mathrm{C}$ for $15 \mathrm{sec} / 65^{\circ} \mathrm{C}$ for $30 \mathrm{sec} / 68^{\circ} \mathrm{C}$ for $6 \mathrm{~min} x 20$ cycles, and $4^{\circ} \mathrm{C}$ hold. The quality of cDNA was evaluated on ethidium bromide-stained $1.2 \%$ agarose gels. In vitro transcription was performed using the Message Machine high yield capped RNA transcription kit (T7 kit) (Ambion, TX, USA). Briefly, the transcription mix, ribonucleotide mix, amplified cDNA, and T7 RNA polymerase were mixed and incubated at $37^{\circ} \mathrm{C}$ for $4 \mathrm{~h}$. The DNA template was degenerated by incubating with DNase I at $37^{\circ} \mathrm{C}$ for $15 \mathrm{~min}(22,23)$. Total RNA $(1 \mu \mathrm{g})$ was extracted from about $5 \mathrm{mg}$ of cell materials and used for the synthesis of $50 \mu \mathrm{g}$ of first strand full-length cDNA, and the latter was stored at $-20^{\circ} \mathrm{C}$. The full-length $\mathrm{cDNA}$ was used to synthesize $500 \mathrm{mg}$ of mRNA by polymerase chain reaction (PCR) amplification and in vitro transcription.

Preparation of $m R N A$ encoding EGFP reporter gene. A pEGFP-N1 Vector (Clontech, CA, USA) was doubly digested with the restricted enzymes HindIII (TaKaRa, Shiga, Japan) and $\operatorname{Not} \mathrm{I}(\mathrm{TaKaRa})$ into $0.8 \mathrm{Kbp}$ - and $3.9 \mathrm{Kbp}$-fragments. The $0.8 \mathrm{Kbp}$-digested fragment (EGFP-dsDNA) was amplified with EGFP-forward primer (5'-CGGAACAAGGGAGC TTCGAATTCTGC-3'), EGFP-reverse primer (5'-TGAGT CAAGGGCTAGCTTTACTTGTACAG-3'), and DNA polymerase, using the following cycling parameters: $94^{\circ} \mathrm{C}$ for $2 \mathrm{~min} x 1 \mathrm{cycle}, 94^{\circ} \mathrm{C}$ for $60 \mathrm{sec} / 33^{\circ} \mathrm{C}$ for $60 \mathrm{sec} / 72^{\circ} \mathrm{C}$ for $60 \mathrm{sec}$ x 8 cycles, and $94^{\circ} \mathrm{C}$ for $60 \mathrm{sec} / 61^{\circ} \mathrm{C}$ for $60 \mathrm{sec} /$ $72^{\circ} \mathrm{C}$ for $60 \mathrm{sec} \times 25$ cycles. The fragments were ligated with the T7 promoter sequence (5'-GACTCGTAATACGA CTCACTATAGGGCCCT-3') at the 5'-end and with the poly (dA) sequence (5'-GACTCAAAGGGA(A) ${ }_{24}$ CCTAAATCG TATGTGTATGATACATA-3') at the 3'-end using Topo tools (Invitrogen, CA, USA). The resulting product was amplified by PCR and followed by in vitro mRNA transcription using the Message Machine high yield capped RNA transcription kit (T7 kit) (Ambion, TX, USA). The final product was used as mRNA encoding the EGFP reporter gene (EGFPmRNA).

Generation of DCs from peripheral blood progenitors. Human DCs were generated according to Romani et al (24) with minor modifications. PBMCs were cultured in serum-free 
RPMI-1640 at $37^{\circ} \mathrm{C}$ and $5 \% \mathrm{CO}_{2}$. After $2 \mathrm{~h}$, the non-adherent cells were removed. The adherent cells were re-suspended in RPMI-1640 medium supplemented with $1 \mathrm{mM}$ L-glutamine, $2 \%$ autologous serum, $800 \mathrm{U} / \mathrm{ml}$ GM-CSF and $500 \mathrm{U} / \mathrm{ml} \mathrm{IL}-4$ in a humidified incubator at $37^{\circ} \mathrm{C}$ and $5 \% \mathrm{CO}_{2}$ for 5 days. This immature DC preparation was used for subsequent RNA introduction in order to generate antigen presenting cells (APCs).

Generation of APCs. RNA was introduced into the cultured immature DCs either by passive pulsing or electroporation. The passive pulsing procedure was modified from Heiser et al (23). Briefly, $10 \mu \mathrm{g}$ of RNA was added to $2 \times 10^{5}$ cells in $200 \mu \mathrm{l}$ of serum-free RPMI-1640 medium and incubated for $45 \mathrm{~min}$ at $37^{\circ} \mathrm{C}$ and $5 \% \mathrm{CO}_{2}$ in a humidified incubator. Electroporation was done using the Gene Pulser II as directed (BioRad, CA, USA). Approximately $2 \times 10^{5}$ cells $\left(1 \times 10^{6}\right.$ cells $\left./ \mathrm{ml}\right)$ in $200 \mu 1$ of serum-free RPMI-1640 medium were placed in a $4 \mathrm{~mm}$ gap chamber along with $10 \mu \mathrm{g}$ of RNA. The mixture was placed in the Gene Pulser II and electroporated at an electrical setting of 150 voltage and $150 \mu \mathrm{F}(25)$. Subsequently, RNA-introduced DCs were allowed to mature in the presence of $1000 \mathrm{U} / \mathrm{ml}$ TNF- $\alpha$ in RPMI-1640 complete medium for 2-3 days. Phenotypic analysis of the matured

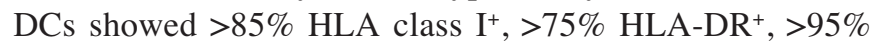
$\mathrm{CD} 80^{+},>75 \% \mathrm{CD} 86^{+},>65 \% \mathrm{CD}^{+} 3^{+}$and $<20 \% \mathrm{CD} 4^{+}$. These mature RNA-introduced DCs were treated with $50 \mu \mathrm{g} / \mathrm{ml}$ mitomycin C (MMC, Kyowa Hakkou Pharmaceutical Co., Ltd., Tokyo), washed 4 times with RPMI-1640 medium and used as APCs. In some experiments, peptide-pulsed DCs were generated from mature DCs by pulsing them with $20 \mu \mathrm{g} /$ $\mathrm{ml}$ of an antigenic epitope peptide for $2 \mathrm{~h}$ and used as APCs (26).

Induction of TRIDAK and PDAK cells. In order to induce tumor-reactive effector cells, the non-adherent cells of PBMCs were stimulated in the presence of $10 \mu \mathrm{g} / \mathrm{ml}$ of IL-7 with MMC-treated tumor RNA-introduced DCs, which were prepared as described above, for 5-7 days at a responder: stimulator ratio of 20:1. In some experiments, this stimulation process was repeated every 7 days. After two stimulations, the cells were further expanded on a flask coated with anti-CD3 antibody $(1 \mu \mathrm{g} / \mathrm{ml})$ in the presence of $40 \mathrm{U} / \mathrm{ml}$ of IL-2. The medium of the culture was half-changed every 3-4 days. The effector cells induced were designated as tumor RNAintroduced dendritic cell-activated killer (TRiDAK) cells. The mature DCs were pulsed with antigenic epitope peptides $(20 \mu \mathrm{g} / \mathrm{ml})$ for $2 \mathrm{~h}$, washed, and used for stimulating nonadherent cells of PBMCs to generate other effector cells designated as peptide-pulsed DC-activated killer (PDAK) cells $(17,18,26)$.

Enzyme-linked immunosorbent assay (ELISA) and immunospot (ELISPOT) assay for IFN- $\gamma$. Antigen recognition of the effector cells, including the LAK cells, TILs, TRiDAK and PDAK cells, was detected by ELISA or ELISPOT assay (R\&D Systems Inc., Minneapolis, USA) specific for IFN- $\gamma$. In ELISA, effector cells $\left(1 \times 10^{6} / \mathrm{ml}\right)$ were stimulated for $72 \mathrm{~h}$ either with MMC-inactivated normal cells, autologous tumor cells, or DCs treated with/without antigen peptide or tumor RNA at a responder/stimulator ratio of 20 , and the culture supernatant was subjected to the assay in triplicate according to the manufacturer's instructions. For the ELISPOT assay, effector cells $\left(4 \times 10^{4}\right)$ were cultured either with MMC-inactivated normal cells, tumor cells, or antigen-presenting DCs at a responder/stimulator ratio of 20 for $48 \mathrm{~h}$ using the ELISPOT kit in triplicate, and IFN- $\gamma$ spots were visualized according to the manufacturer's instructions.

Cytotoxicity assay. To examine the cytotoxic activity of effector cells, a conventional $4-\mathrm{h}{ }^{51} \mathrm{Cr}$ release assay was performed. Target cells, including normal cells, tumor cells and DCs, were labeled with ${ }^{51} \mathrm{Cr}(100 \mu \mathrm{Ci})$ for $2 \mathrm{~h}$, washed 3 times, and plated onto round-bottomed 96 -well microtiter plates at a concentration of $1 \times 10^{4}$ cells $/ 0.1 \mathrm{ml}$. Effector cells were added over the target cells at various concentrations in a final volume of $0.2 \mathrm{ml}$. In some experiments, this incubation was performed in the presence of $10 \mu \mathrm{g} / \mathrm{ml}$ anti-HLA class I, class II, -TCR antibodies or control Ig. After $4 \mathrm{~h}$ of incubation at $37^{\circ} \mathrm{C}$, the release of ${ }^{51} \mathrm{Cr}$ in the supernatant was measured by an automated gamma counter (Aloka, Tokyo, Japan). The mean percentage of the specific lysis of the triplicate wells was calculated by the following formula: (experimental release spontaneous release)/(maximum release - spontaneous release) $\mathrm{x} 100$. The experimental release was obtained from the wells of the effector cells plus the target cells, and the spontaneous release was obtained from the wells of the target cells alone and was around $15 \%$ of the maximum release, which was obtained from the wells in which $2 \%$ Triton X-100 was added over the target cells instead of effector cells.

Flow cytometric analysis. EGFP-mRNA and the Cellstain double staining kit (Dojindo, Kumamoto, Japan) were used to evaluate the RNA introduction efficiency into immature DCs (24). Briefly, the EGFP expression rate in EGFP-mRNAintroduced DCs (DC/EGFP-mRNA) was assessed $48 \mathrm{~h}$ after electroporation by flow cytometric analysis using FACSCalibur (Becton-Dickinson, NJ, USA). The cell viability rate was assessed by calcein and propidium iodide (PI) double staining and flow cytometric analysis. Immediately after electroporation, the DCs were stained using the Cellstain double staining kit according to the manufacturer's protocol. Prior to flow cytometric analysis, Calcein-acetyoxymethyl (Calcein$\mathrm{AM}$ ) and PI were added at a final concentration of 2 and $4 \mu \mathrm{M}$, respectively, directly into the DCs suspended in RPMI-1640 complete medium and incubated for $15 \mathrm{~min}$ at $37^{\circ} \mathrm{C}$. The fluorescence of calcein in viable cells was read at a $490 \mathrm{~nm}$ excitation and $530 \mathrm{~nm}$ emission setting. The fluorescence of PI in the dead cells was read at a $530 \mathrm{~nm}$ excitation and $590 \mathrm{~nm}$ emission setting. The percentage of the EGFP-mRNA introduction efficiency was calculated according to the formula: (EGFP expression rate) x (cell viability rate) $\mathrm{x} 100$. Flow cytometry was also performed to determine the phenotypes of the TRiDAK cells $\left(5 \times 10^{5}\right)$ using anti-CD4, -CD8, and -CD25 antibodies.

Statistics. Results are expressed as the mean \pm SD. Statistical analysis was conducted by unpaired Student's t-test using StatView software (version 5) on a Macintosh computer. A value of $\mathrm{p}<0.05$ was considered statistically significant. 


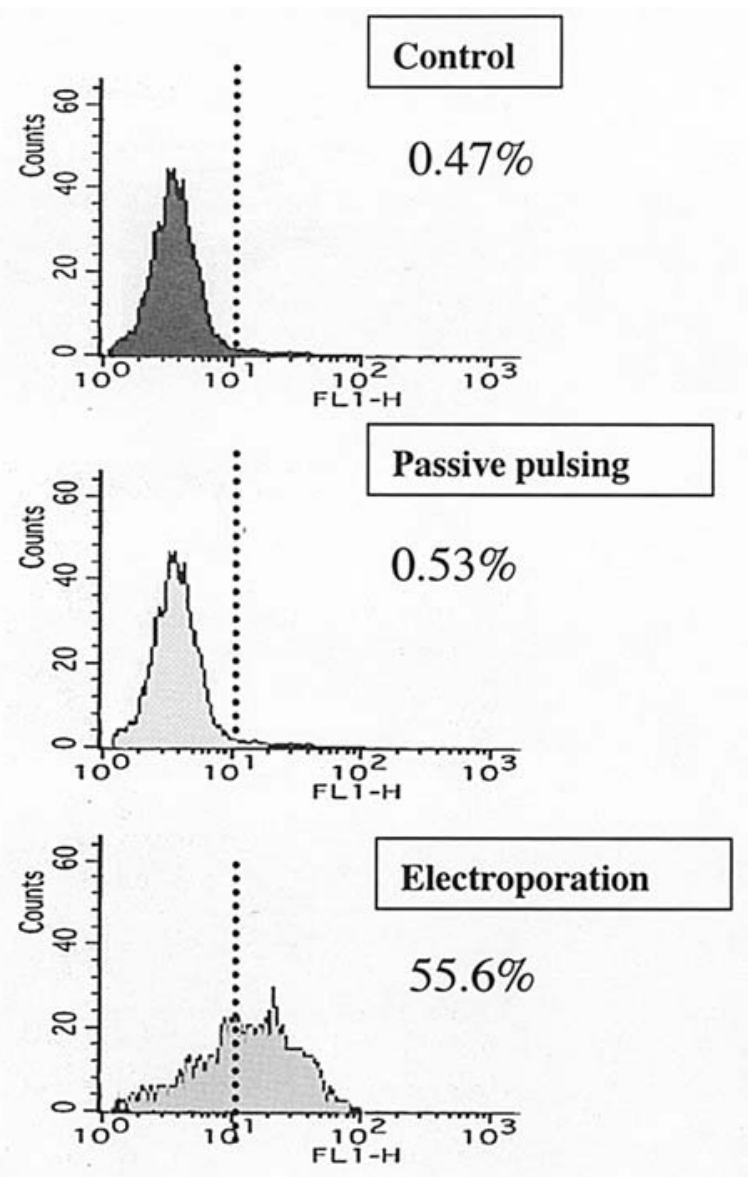

Figure 1. Introduction of EGFP mRNA into cultured DCs by electroporation. DCs were induced from an adherent fraction of PBMCs with GM-CSF and IL-4. EGFP mRNA was introduced into the DCs either by passive pulsing or electroporation at an electrical setting of $150 \mathrm{~V}$ and $150 \mu \mathrm{F}$. The viability of EGFP mRNA-introduced DCs was $78.7 \%$. Gene introduction efficiency was assessed by flow cytometry.

\section{Results}

Efficient introduction of mRNA into cultured DCs by electroporation. First, RNA introduction into cultured DCs from healthy donors was confirmed using EGFP mRNA (Fig. 1). As compared to the control, passive pulsing of the EGFP mRNA showed $0.53 \%$ gene introduction efficiency. However, the EGFP mRNA introduction into DCs using electroporation demonstrated $55.6 \%$. Viability of the DCs at this condition was determined to be $78.7 \%$, as described in Materials and methods. This was highly reproducible in at least two other independent experiments.

Tumor specific recognition by TRiDAK cells. Using the above tumor RNA-introduced DCs, TRiDAK cells were generated and their tumor reactivity was evaluated using ELISPOT assay (Fig. 2A and B). When using the RNA of an MKN45 cell line and PBMCs from healthy donors (MKN45-TRiDAK), the TRiDAK cells showed approximately $1,200 \mathrm{IFN}-\gamma$ spots in the presence of MKN45 tumor cells but $<50$ spots in the absence of the tumor cells (Fig. 2A). LAK cells that were generated with an anti-CD3 plus IL-2 culture system without tumor antigens, effector cells activated with mock DCs (mock
A) MKN45-TRiDAK

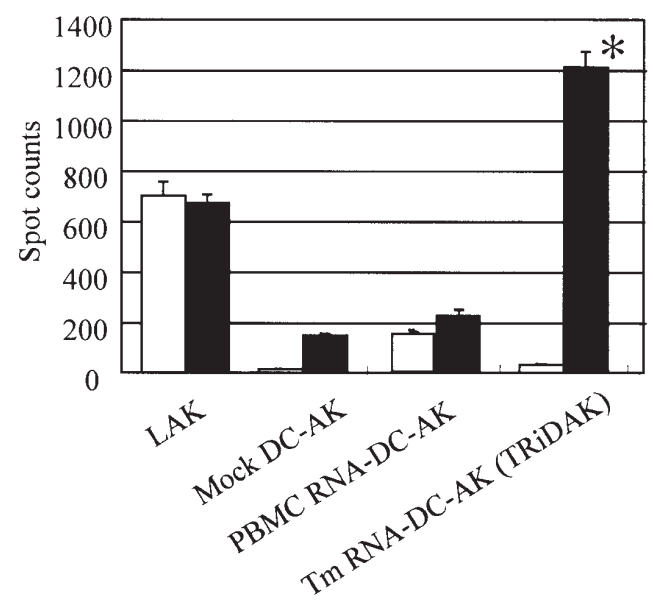

B) As-TRiDAK

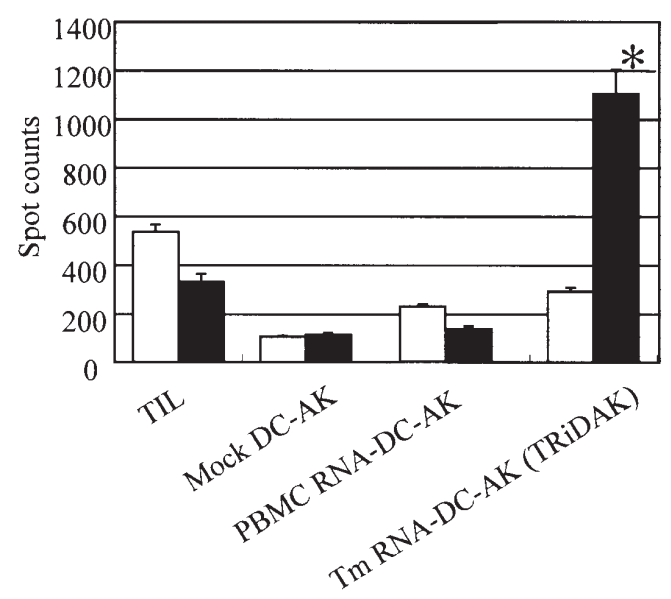

Figure 2. Tumor recognition by TRiDAK cells. Effector cells were generated by using cultured DCs and mRNAs from A) a gastric cancer cell line (MKN45) or B) ascites tumor cells (AS), as indicated. Tumor recognition was assessed by ELISPOT assay in the presence (black boxes) or absence (open boxes) of tumor cells. A significant difference between the values in the presence and absence of tumor cells, ${ }^{*} \mathrm{p}<0.01$.

DC-AK), or effector cells activated with normal cell-derived RNA-introduced DCs (PBMC RNA-DC-AK) demonstrated no MKN45-specific IFN- $\gamma$ spots (Fig. 2A). Similar results were obtained when ascites tumor cells and cultured autologous DCs were employed in the investigation (Fig. 2B). TRiDAK cells generated from gastric cancer patients (AS-TRiDAK) showed a significant production of IFN- $\gamma$ spots in the presence of autologous ascites tumor cells, but not without tumor cells. However, TILs from autologous malignant ascites, mock DCstimulated effector cells (mock DC-AK), or normal RNAintroduced DC-stimulated effector cells (PBMC RNA-DC-AK) failed to show tumor-specific IFN- $\gamma$ spot production. These were reproductively confirmed in two experiments using an MKN45 tumor cell line and donor PBMCs, and in 5 of 6 experiments from gastric cancer patients with malignant ascites (Table I). The tumor-specific reactivity of TRiDAK cells was augmented when stimulation with tumor RNAintroduced DCs was repeated twice in the healthy donor 
Table I. IFN- $\gamma$ spots of TRiDAK cells in the presence of tumor cells.

\begin{tabular}{lccc}
\hline TRiDAK cells & Stimulation & Tumor (-) & Tumor (+) \\
\hline MKN45/donor 1 & x1 & 45 & 1271 \\
MKN45/donor 2 & x1 & 34 & 266 \\
& x2 & & 400 \\
As-1 & xl & 303 & 1098 \\
As-2 & xl & 149 & 411 \\
As-3 & xl & 127 & 274 \\
As-4 & xl & 135 & 523 \\
As-5 & xl & 262 & 275 \\
As-6 & x1 & 27 & 52 \\
& x2 & & 278 \\
\hline
\end{tabular}

TRiDAK cells were generated using cultured DCs and mRNAs from an MKN45 gastric cancer cell line or ascites tumor cells. Tumor recognition was assessed by ELISPOT assay in the presence or absence of tumor cells.

Table II. Cytotoxic activity and phenotype of TRiDAK cells.

\begin{tabular}{lcccc}
\hline TRiDAK & $\begin{array}{c}\text { Cytotoxicity } \\
(\%)\end{array}$ & \multicolumn{3}{c}{ Phenotype (\%) } \\
\cline { 3 - 5 } & & CD4 & CD8 & CD4 $^{+}{ }^{2}$ 25 $5^{+}$ \\
\hline Case 1 & 5 & 98.4 & 0.4 & 98.3 \\
Case 2 & 72 & 40.0 & 59.9 & 58.7 \\
Case 3 & 98 & 19.8 & 66.4 & 22.4 \\
\hline
\end{tabular}

TRiDAK cells were generated using cultured DCs and mRNA from ascites tumor cells. Cytotoxicity assay was performed using a ${ }^{51} \mathrm{Cr}$-releasing assay, and phenotypic analysis was done using flow cytometry.

system and in the system of patients with malignant ascites (Table I).

TRiDAK cells do not recognize normal cells. When using TRiDAK cells in cancer immunotherapy, the reactivity of TRiDAK cells with normal cells is of importance. The reactivity of TRiDAK cells with normal cells was investigated (Fig 3). From 3 independent experiments, the TRiDAK cells reproducibly showed significant productions of IFN- $\gamma$ only in the presence of autologous tumor cells $(\sim 2,700-4,000 \mathrm{pg} / \mathrm{ml})$. However, the TRiDAK cells did produce quite low levels of IFN- $\gamma(\sim 200-1,000 \mathrm{pg} / \mathrm{ml})$ in the presence of autologous PBMCs. Significant differences were found between these values $(\mathrm{p}<0.05)$.

RNA-specific cytotoxic activity of effector cells stimulated with EGFP mRNA-introduced DCs. The RNA specificity of effector cells stimulated with RNA-introduced DCs was examined

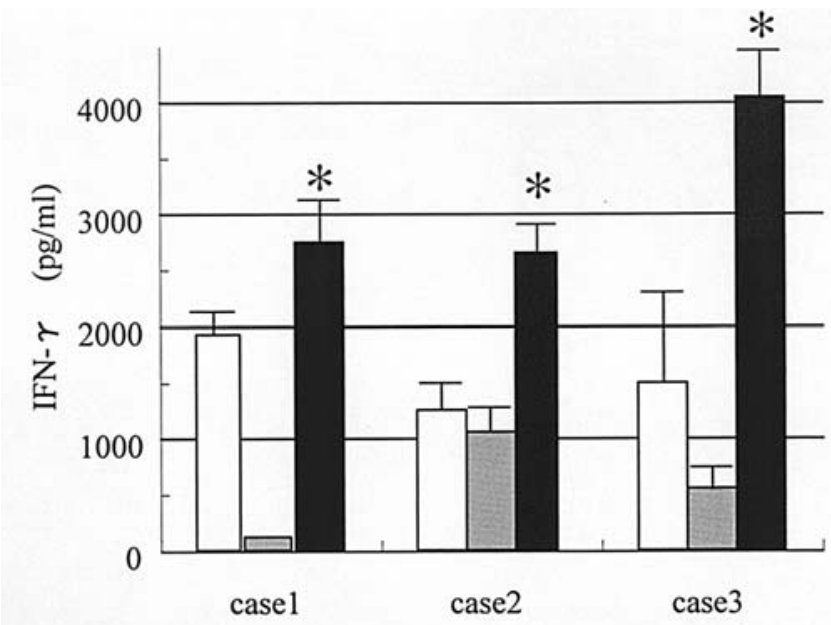

Figure 3. TRiDAK cells do not recognize normal PBMCs. TRiDAK cells were generated using cultured DCs and mRNAs from ascites tumor cells. The target recognition of TRiDAK cells was assessed by IFN- $\gamma$ production in the supernatant at an effector-to-target ratio of 10. The target cells used were none (white), autologous PBMCs (gray), and autologous tumor cells (black). A significant difference from the values against the control or PBMC targets, ${ }^{*} \mathrm{p}<0.05$.

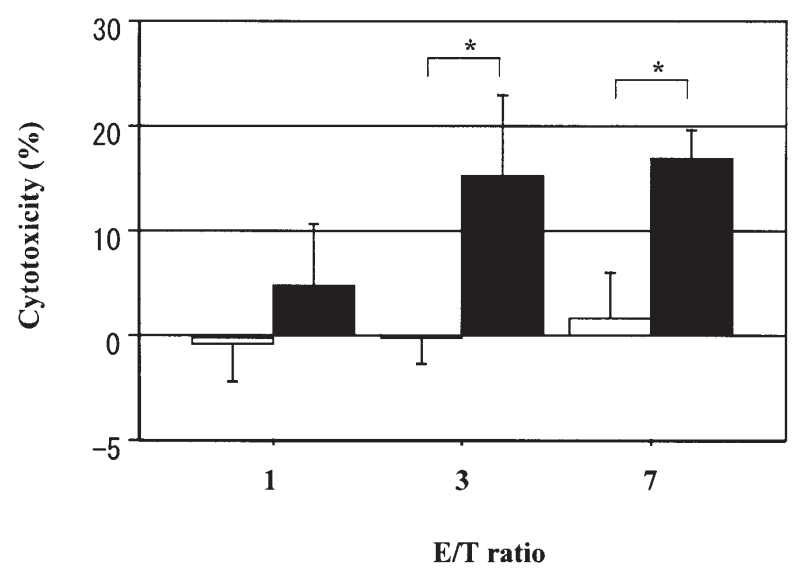

Figure 4. RNA-specific cytotoxic activity of TRiDAK cells. Effector cells were generated using cultured DCs and mRNA either from gastric cancer cells (white) or an EGFP mRNA (black). Cytotoxicity assay was performed against EGFP mRNA-introduced DCs as a target at various effector-totarget ratios. The significant difference, ${ }^{*} \mathrm{p}<0.05$.

(Fig. 4). Effector cells activated with EGFP mRNA-introduced DCs were capable of lysing target cells, which were EGFP mRNA-introduced DCs, in a dose-dependent fashion. However, TRiDAK cells that were generated with gastric cancer-derived RNA-DCs could not kill the target of EGFP mRNA-introduced DCs. There were significant differences in the values of cytotoxic activity against EGFP mRNAintroduced DCs as a target between effector cells activated with EGFP mRNA-introduced DCs and TRiDAK cells from gastric cancer cells $(\mathrm{p}<0.05)$.

Involvement of HLA class I, class II, or T-cell receptor molecules in cytotoxicity machinery of TRiDAK cells. To determine the involvement of HLA class I, class II, or T-cell 
Table III. Comparison between PDAK cells and TRiDAK cells.

\begin{tabular}{|c|c|c|}
\hline \multirow[b]{2}{*}{ Effector cells } & \multicolumn{2}{|c|}{$\mathrm{IFN}-\gamma(\mathrm{pg} / \mathrm{ml})$} \\
\hline & Tumor (-) & Tumor (+) \\
\hline \multicolumn{3}{|l|}{ Healthy donor } \\
\hline Flu-PDAK & 100 & 112 \\
\hline CEA652(9)-PDAK & 98 & 640 \\
\hline \multicolumn{3}{|l|}{ Ascites patient } \\
\hline Flu-PDAK & 52 & 40 \\
\hline \multicolumn{3}{|l|}{ CEA-PDAK } \\
\hline CEA10(10) & - & 31 \\
\hline CEA101(9) & - & 29 \\
\hline CEA234(9) & - & 43 \\
\hline CEA268(10) & - & 33 \\
\hline CEA318(9) & - & 37 \\
\hline CEA425(9) & - & 44 \\
\hline CEA426(10) & - & 50 \\
\hline CEA590(9) & - & 25 \\
\hline CEA604(10) & - & 38 \\
\hline CEA652(9) & 59 & 64 \\
\hline HER2-PDAK & - & 61 \\
\hline TRiDAK & 124 & 1147 \\
\hline \multicolumn{3}{|c|}{$\begin{array}{l}\text { PDAK cells were generated using cultured DCs and HLA-A24- } \\
\text { restricted CEA, Her2, or Flu-epitope peptides, as indicated, in a } \\
\text { healthy donor (HLA-A24) and a patient As- } 4 \text { in Table I who had } \\
\text { HLA-A24 and a positive serum CEA level. TRiDAK cells were } \\
\text { generated using DCs and mRNA from autologous ascites tumor } \\
\text { cells. Target recognition of PDAK and TRiDAK cells was assessed } \\
\text { by IFN- } \gamma \text { production in the presence or absence of the ascites tumor } \\
\text { cells. }\end{array}$} \\
\hline
\end{tabular}

receptor molecules in the cytotoxic machinery of TRiDAK cells, blocking experiments with monoclonal antibodies were performed in a cytotoxicity assay (Fig. 5). TRiDAK cells lysed gastric cancer cells reproducibly, and this was not affected by the addition of a control antibody. However, the addition of either anti-HLA class I, class II, or T-cell receptor antibodies in the cytotoxicity assay abrogated $\sim 70-95 \%$ cytotoxic activity of the TRiDAK cells generated. There were significant differences between these values $(\mathrm{p}<0.01)$.

Cytotoxic activity and phenotypes of TRiDAK cells. The cytotoxic activity and phenotypes of TRiDAK cells were examined (Table II). TRiDAK cells that had only 5\% cytotoxic activity expressed $98 \%$ of CD4 phenotype, but $0.4 \%$ of the CD8 phenotype. However, TRiDAK cells that expressed $98 \%$ cytotoxic activity showed $19.8 \%$ CD4 and $66.4 \%$ CD8 phenotypes. Two-color flow cytometric analysis using anti-CD4 and $-\mathrm{CD} 25$ antibodies indicated that most $\mathrm{CD}^{+}$cells of TRiDAK cells expressed CD25 molecules.

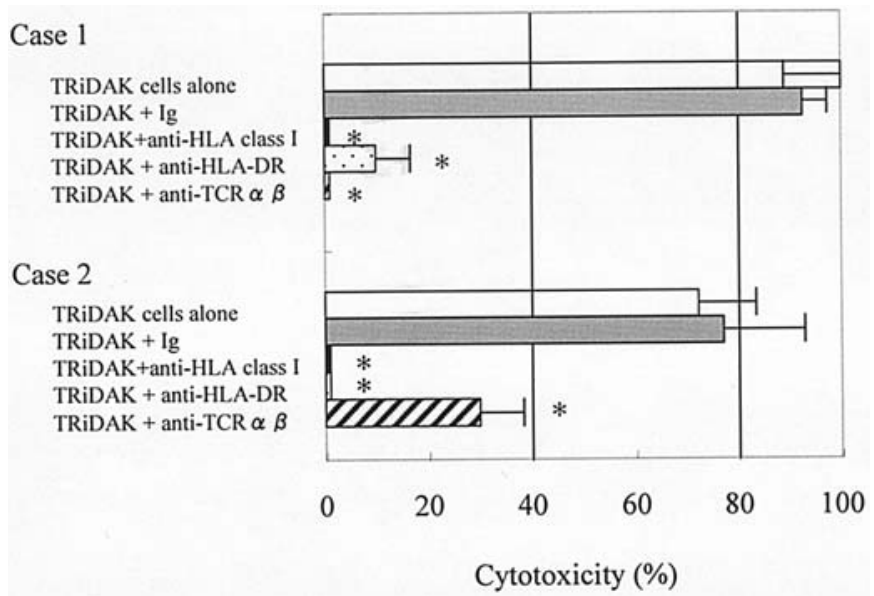

Figure 5. Involvement of HLA class I, II, and T-cell receptor molecules in target cell lysis of TRiDAK cells. TRiDAK cells were generated using cultured DCs and mRNAs from ascites tumor cells. Cytotoxicity assay was performed against autologous tumor cells at an effector-to-target ratio of 40 in the presence of antibodies. The antibodies used were none (white), mouse Ig (gray), anti-HLA class I (black), anti-HLA-DR (dotted), and anti-TCR (striped) antibodies. A significant difference from the value with control Ig, * $\mathrm{p}<0.01$.

Comparison between PDAK and TRiDAK cells. Effector cells were generated in a healthy donor (HLA-A24) or a gastric cancer patient with malignant ascites [As-4, HLA-A24, CEA(+)] either with a peptide-DC system (PDAK cells) or tumor RNA-DC system (TRiDAK cells), and tumor-specific IFN- $\gamma$ production was examined (Table III). In the healthy donor experiment, the CEA-PDAK cells showed IFN- $\gamma$ responses in the presence of the patient's ascites tumor cells, but not in the absence of the tumor cells. In the gastric cancer patient, however, 10 kinds of CEA-PDAK cells that were generated using an HLA-A24-restricted CEA peptide panel produced IFN- $\gamma$ at a low level $(25-64 \mathrm{pg} / \mathrm{ml})$ in the presence of autologous tumor cells, comparable to that of control FluPDAK cells $(40 \mathrm{pg} / \mathrm{ml})$. The Her2-PDAK cells did not show any significant IFN- $\gamma$ production $(61 \mathrm{pg} / \mathrm{ml})$. However, the TRiDAK cells that were generated using cultured autologous DCs and tumor mRNA produced $1,147 \mathrm{pg} / \mathrm{ml}$ of IFN- $\gamma$ in the presence of the tumor cells, quite different from $124 \mathrm{pg} /$ $\mathrm{ml}$ of IFN- $\gamma$ in the absence of the tumor cells.

\section{Discussion}

In this study, we have shown the generation of tumor antigenreactive effector cells, named TRiDAK cells, using the tumor RNA-introduced DCs and peripheral blood lymphocytes in both a gastric cancer cell line and gastric cancer patients with malignant effusion. Tumor RNA could efficiently be introduced into cultured DCs by electroporation. The approach using amplified tumor-RNA and an mRNA delivery system using electroporation has several advantages: 1) DCs can be introduced to levels comparable with transduction by recombinant viruses, such as poxviruses (27) or adenoviruses (28), without the problems associated with viral vectors (29), 2) DCs can be introduced with the total antigenic spectrum using mRNA extracted from cancer cells without prior identification of tumor-associated antigens (TAAs), 3) RNA can be amplified 
by PCR to provide an unlimited supply of TAAs from a small amount of clinical tumor tissue (22), and 4) RNA has a short cellular half-life and lacks the potential to integrate into the host genome, thus, the potential safety hazard in the context of clinical therapeutic trials can be avoided (30). Although Schaft et al (31) demonstrated an optimized RNA transfection into DCs after rather than before their maturation, our results showed the efficient introduction of RNA into cultured immature DCs, consistent with other studies $(32,33)$.

We showed that tumor RNA-introduced DCs could reproducibly stimulate lymphocytes to be tumor-reactive effector TRiDAK cells. TRiDAK cells produced IFN- $\gamma$ spots only in the presence of tumor cells, not in their absence. Cultured mock DCs or normal cell RNA-introduced DCs failed to generate effector cells reactive with tumor cells. TRiDAK cells secreted IFN- $\gamma$ when stimulated with tumor cells, but not with normal cells. These results indicate the nature of reactivity of TRiDAK cells specific for tumor cells, but not for normal cells, which is consistent with previous reports (13-16). Moreover, several phase I clinical trials using tumor mRNA-introduced DCs showed no apparent adverse effects or dose-limiting toxicities, including autoimmune toxicity (34). Therefore, there is a strong possibility that the tumor RNA-introduced DCs may not stimulate the forbidden clones that will react with self antigens. This may augment the possible clinical application of TRiDAK cells in the adoptive immunotherapy of cancer.

It was observed in this study that effector cells stimulated with EGFP mRNA-introduced DCs recognized EGFPexpressing cells, but the effector cells stimulated with irrelevant mRNA-introduced DCs did not, indicating the RNA-specific antigen presentation by DCs, and thereby RNA-specific antigen recognition by TRiDAK cells. This is consistent with other studies showing that an exogenous mRNA-DC system can prime precursors and induce antigenspecific CTLs in an introduced mRNA-specific manner $(35,36)$. This indicates that tumor RNA that may contain numerous tumor antigen-coding genes must be able to stimulate numerous CTL precursors that have $\mathrm{T}$ cell receptors reactive with each tumor antigen, and suggests that an RNA-DC system is superior to a peptide-DC system in terms of tumor-reactive T-cell activation. Actually, our results showed that TRiDAK cells reactive with autologous tumor cells could be generated in a CEA-positive gastric cancer patient with malignant effusion, in whom we failed to generate effector cells even with CEA antigen peptides and cultured DCs. Moreover, in a study by Mine et al (12), notable tumor responses were demonstrated in peptide vaccine trials not using single but multiple peptides that were able to stimulate patients' PBMCs to produce IFN- $\gamma$, indicating the requirement of multiple epitope usage in the immunotherapy of clinical tumors. These results suggest that adoptive immunotherapy of cancer using TRiDAK cells may be superior to that using a peptide-DC culture system (26) because of the heterogenic nature of clinical tumors.

Tumor killing activity of TRiDAK cells was inhibited not only with the anti-HLA class I antibody but also with the anti-HLA class II antibody, indicating that tumor RNAintroduced DCs can not only stimulate CD8 ${ }^{+}$CTL responses but also antigen-reactive $\mathrm{CD} 4^{+} \mathrm{T}$-cell responses. Nair et al (14) and Weissman et al (36) demonstrated that the antigenic
mRNA transfection of DCs delivers encoded antigen to MHC class I and class II molecules, but that the peptide-DC system can stimulate only potent $\mathrm{CD} 8^{+} \mathrm{CTL}$ responses, not $\mathrm{CD} 4^{+}$ $\mathrm{T}$-cell responses. Bonehill et al (37) reported the presentation of the MAGE-A3 antigen simultaneously in HLA class I and class II molecules by mRNA-electroporated DCs, which is consistent with our observation. Zhao et al (38) demonstrated that a short incubation of mRNA-transfected DCs enhances the presentation of mRNA-encoded class II epitopes and the activation of $\mathrm{CD}^{+}{ }^{+} \mathrm{T}$-cell responses in vitro and in vivo to stimulate potent and longer lasting $\mathrm{CD} 8^{+} \mathrm{CTL}$ responses by enhancing the antitumor efficacy of DC-based tumor vaccination protocols. These observations together indicate the importance of activating class II as well as class I pathways by tumor RNA-DC system in the immunotherapy of cancer. Although activation of both the class I and class II pathways is certainly important, it should be noted that in our study, the TRiDAK cells from one gastric cancer patient that did not have any tumor killing activity expressed only the CD4 phenotype. This $\mathrm{CD}^{+}$population was comprised of $\mathrm{CD} 4{ }^{+} \mathrm{CD} 25^{+}$cells, which have been known as activated $\mathrm{T}$ cells and regulatory $\mathrm{T}$ (T-reg) cells $(39,40)$. The possible induction of T-reg cells during TRiDAK cell generation may also explain why TRiDAK cells did not react with normal cells, as shown above, because tumor mRNA encodes not only mutated oncogenic antigens but also some normal self-antigen proteins, and T-reg cells have been known to play a pivotal role in inhibiting host immune responses against self antigens. Antony et al (41) have demonstrated that $\mathrm{CD} 4^{+}$helper T-cells can help break tolerance to persisting self antigens and treat established tumors through an IL-2-dependent mechanism, but requires the simultaneous absence of T-reg cells to be effective. Dudley et al (42) reported in the adoptive immunotherapy trial of malignant melanoma using TILs that drastic tumor responses are evidenced in the pre-treatment of patients with non-myeloablative lymphodepleting chemotherapy, which may cause the down-regulation of T-reg cells. Thus, gaining molecular and cellular understanding of the possible mechanism for the induction and regulation of T-reg cells is an important issue to be clarified in our TRiDAK cell generation system for future adoptive immunotherapy trials.

In summary, the use of autologous tumor mRNAintroduced DCs can generate anti-tumor effector cells, named tumor RNA-introduced DC-activated killer (TRiDAK) cells, without inducing autoreactive immune cells. To our knowledge, this is the first study investigating anti-tumor effector cell generation using cultured DCs and mRNA from gastric cancer cells. An adoptive immunotherapeutic approach using TRiDAK cells permits broad applicability against various tumor-bearing patients without prior identification of HLA phenotypes and epitope peptides. This approach offers an unlimited supply of tumor mRNA by in vitro amplification from a limited source of tumor cells. Collectively, the approach using the TRiDAK cell generation system offers novel possibilities for the antigenspecific immunotherapy of gastric cancer.

\section{Acknowledgements}

We would like to thank Miss Yoshie Nakatani for excellent technical assistance in the preparation of the report. 


\section{References}

1. Parkin DM: Global cancer statistics in the year 2000. Lancet Oncol 9: 533-543, 2001.

2. Peddanna N, Holt $\mathrm{S}$ and Verma RS: Genetics of gastric cancer. Anticancer Res 15: 2055-2064, 1995.

3. Van der Bruggen $\mathrm{P}$, Traversari C, Chomez $\mathrm{P}$, Lurquin C, De Plaen E, van den Eynde B, Knuth A and Boon T: A gene encoding an antigen recognized by cytotoxic $\mathrm{T}$ lymphocytes on a human melanoma. Science 254: 1643-1647, 1991.

4. Mescher MF: Molecular interactions in the activation of effector and precursor cytotoxic T lymphocytes. Immunol Rev 146: $177-210,1995$.

5. Kono K, Takahashi A, Sugai H, Fujii H, Choudhury AR, Kiessling $\mathrm{R}$ and Matsumoto $\mathrm{Y}$ : Dendritic cells pulsed with HER-2/neu-derived peptides can induce specific T-cell responses in patients with gastric cancer. Clin Cancer Res 8: 3394-3400, 2002.

6. Wang Y, Wu XJ, Zhao AL, Yuan YH, Chen YT, Jungbluth AA, Gnjatic S, Santiago D, Ritter G, Chen WF, Old LJ and Ji JF: Cancer/testis antigen expression and autologous humoral immunity to NY-ESO-1 in gastric cancer. Cancer Immun 4: 11$17,2004$.

7. Sasada T, Takedatsu H, Azuma K, Koga M, Maeda Y, Shichijo S, Shoumura H, Hirai T, Takabayashi A and Itoh K: Immediate early response gene $\mathrm{X}-1$, a stress-inducible antiapoptotic gene, encodes cytotoxic T-lymphocyte (CTL) epitopes capable of inducing human leukocyte antigen-A33-restricted and tumorreactive CTLs in gastric cancer patients. Cancer Res 64: 2882-2888, 2004.

8. Watanabe T, Suda T, Tsunoda T, Uchida N, Ura K, Kato T, Hasegawa S, Satoh S, Ohgi S, Tahara H, Furukawa Y and Nakamura Y: Identification of immunoglobulin superfamily 11 (IGSF11) as a novel target for cancer immunotherapy of gastrointestinal and hepatocellular carcinomas. Cancer Sci 96: 498-506, 2005.

9. Idenoue S, Hirohashi Y, Torigoe T, Sato Y, Tamura Y, Hariu H, Yamamoto M, Kurotaki T, Tsuruma T, Asanuma H, Kanaseki T, Ikeda H, Kashiwagi K, Okazaki M, Sasaki K, Sato T, Ohmura T, Hata F, Yamaguchi K, Hirata K and Sato N: A potent immunogenic general cancer vaccine that targets survivin, an inhibitor of apoptosis proteins. Clin Cancer Res 11: 1474-1482, 2005.

10. Sato Y, Shomura H, Maeda Y, Mine T, Une Y, Akasaka Y, Kondo M, Takahashi S, Shinohara T, Katagiri K, Sato M, Okada S, Matsui K, Yamada A, Yamana H, Itoh K and Todo S: Immunological evaluation of peptide vaccination for patients with gastric cancer based on pre-existing cellular response to peptide. Cancer Sci 94: 802-808, 2003.

11. Chen Y, Wu K, Guo C, Liu C, Han S, Lin T, Ning X, Shi R, Shi Y and Fan D: A novel DNA vaccine containing four mimicry epitopes for gastric cancer. Cancer Biol Ther 4: 308-312, 2005.

12. Mine T, Gouhara R, Hida N, Imai N, Azuma K, Rikimaru T, Katagiri K, Nishikori M, Sukehiro A, Nakagawa M, Yamada A, Aizawa H, Shirouzu K, Itoh K and Yamana H: Immunological evaluation of CTL precursor-oriented vaccines for advanced lung cancer patients. Cancer Sci 94: 548-556, 2003.

13. Boczkowski D, Nair SK, Synder D and Gilboa E: Dendritic cells pulsed with RNA are potent antigen-presenting cells in vitro and in vivo. J Exp Med 184: 465-472, 1996.

14. Nair SK, Boczkowski D, Morse M, Cumming RI, Lyerly HK and Gilboa E: Induction of primary carcinoembryonic antigen (CEA)-specific cytotoxic T lymphocytes in vitro using human dendritic cells transfected with RNA. Nat Biotechnol 16: 364-369, 1998.

15. Ashley D, Faiola B, Nair S, Hale LP, Bigner DD and Gilboa E: Bone marrow-generated dendritic cell pulsed with tumor extracts or tumor RNA induce anti-tumor immunity against central nervous system tumors. J Exp Med 186: 1177-1182, 1997.

16. Gilboa E, Nair SK and Lyerly H: Immunotherapy of cancer with dendritic cell-based vaccines. Cancer Immunol Immunother 46: 82-87, 1998.

17. Yamaguchi Y, Ohshita A, Kawabuchi Y, Ohta K, Shimizu K, Minami K, Hihara J, Miyahara E and Toge T: Adoptive immunotherapy of cancer using activated autologous lymphocytescurrent status and new strategies. Hum Cell 16: 183-189, 2003.

18. Yamaguchi Y, Ohta K, Kawabuchi Y, Ohshita A, Okita R, Okawaki M, Hironaka K, Matsuura K and Toge T: Feasibility study of adoptive immunotherapy for metastatic lung tumors using peptide-pulsed dendritic cell-activated killer (PDAK) cells. Anticancer Res 25: 2407-2415, 2005.
19. Gaugler B, van den Eynde B, van der Bruggen P, Romero P, Gaforio JJ, De Plaen E, Lethe B, Brasseur F and Boon T: Human gene MAGE-3 codes for an antigen recognized on a melanoma by autologous cytolytic T lymphocytes. J Exp Med 179: 921-930, 1994.

20. Zimmermann W, Ortlieb B, Friedrich R and von Kleist S: Isolation and characterization of cDNA clones encoding the human carcinoembryonic antigen reveal a highly conserved repeating structure. Proc Natl Acad Sci USA 84: 2960-2964, 1987.

21. Ikuta Y, Okugawa T, Furugen R, Nagata Y, Takahashi Y, Wang L, Ikeda H, Watanabe M, Imai S and Shiku H: A HER2/ NEU-derived peptide, a K(d)-restricted murine tumor rejection antigen, induces HER2-specific HLA-A2402-restricted CD8(+) cytotoxic T lymphocytes. Int J Cancer 87: 553-558, 2000.

22. Boczkowski D, Nair SK, Nam JH, Lyerly HK and Gilboa E: Induction of tumor immunity and cytotoxic $\mathrm{T}$ lymphocyte responses using dendritic cells transfected with messenger RNA amplified from tumor cells. Cancer Res 60: 1028-1034, 2000.

23. Heiser A, Maurice MA, Yancey DR, Wu NZ, Dahm P, Pruitt SK, Boczkowski D, Nair SK, Ballo MS, Gilboa E and Vieweg J: Induction of polyclonal prostate cancer-specific CTL using dendritic cells transfected with amplified tumor RNA. J Immunol 166: 2953-2960, 2001.

24. Romani N, Gruner S, Brang D, Kampgen E, Trockenbacher B, Lenz A, Konwalinka G, Fritsch PO, Steinman RM and Schuler G: Proliferating dendritic cell progenitors in human blood. J Exp Med 180: 83-93, 1994.

25. Minami K, Yamaguchi Y, Ohshita A, Kawabuchi Y, Ohta K, Hihara $J$ and Toge $T$ : Generation of antigen presenting cells using cultured dendritic cells and amplified autologous tumormRNA. Oncology (In press).

26. Ohta K, Yamaguchi Y, Shimizu K, Miyahara E and Toge T: Novel system for generation cytotoxic effector lymphocytes using carcinoembryonic antigen (CEA) peptide and cultured dendritic cells. Anticancer Res 22: 2597-2606, 2002.

27. Dietz AB and Vuk PS: High efficiency adenovirus-mediated gene transfer to human dendritic cells. Blood 91: 392-398, 1998.

28. Jenne L, Hauser C, Arrighi JF, Saurat JH and Hugin AW: Poxvirus as avector to transduce human dendritic cells for immunotherapy: abortive infection but reduced APC function. Gene Ther 7: 1575-1583, 2000.

29. Lu D, Benjamin R, Kim M, Conry RM and Curiel DT: Optimaization of methods to achieve mRNA-mediated transfection of tumor cells in vitro and in vivo employing cationic liposome vectors. Gene Ther 1: 245-252, 1994.

30. Heiser A, Dahm P, Yancey DR, Maurice MA, Boczkowski D, Nair SK, Gilboa E and Vieweg J: Human dendritic cells transfected with RNA encoding prostate-specific antigen stimulate prostate-specific CTL responses in vitro. J Immunol 164: 5508-5514, 2000.

31. Schaft N, Dorrie J, Thumann P, Beck VE, Muller I, Schultz ES, Kampgen E, Dieckmann D and Schuler G: Generation of an optimized polyvalent monocyte-derived dendritic cell vaccine by transfecting defined RNAs after rather than before maturation. J Immunol 174: 3087-3097, 2005

32. Van Tendeloo VF, Ponsaerts P, Lardon F, Nijs G, Lenjou M, Van Broeckhoven C, van Bockstaele DR and Berneman ZN: Highly efficient gene delivery by mRNA electroporation in human hematopoietic cell: superiority to lipofection and passive palsing of mRNA and to electroporation of plasmid cDNA for tumor antigen loading of dendritic cells. Blood 98: 49-56, 2001.

33. Kalady MF, Onaitis MW, Padilla KM, Emani S, Tyler DS and Pruitt SK: Enhamced dendritic cell antigen presentation in RNA-based immunotherapy. J Surg Res 105: 17-24, 2002.

34. Su Z, Dannull J, Heiser A, Yancey D, Pruitt S, Madden J, Coleman D, Niedzwiecki D, Gilboa E and Vieweg J: Immunological and clinical responses in metastatic renal cancer patients vaccinated with tumor RNA-transfected dendritic cells. Cancer Res 63: 2127-2123, 2003

35. Heiser A, Maurice MA, Yancey DR, Coleman DM, Dahm P and Vieweg J: Human dendritic cells transfected with renal tumor RNA stimulate polyclonal T-cell responses against antigens expressed by primary and metastatic tumors. Cancer Res 61: 3388-3393, 2001

36. Weissman D, Ni H, Scales D, Dude A, Capodici J, McGibney K, Abdool A, Isaacs SN, Cannon G and Kariko K: HIV gag mRNA transfection of dendritic cells (DC) delivers encorded antigen to MHC class I and II molecules, causes DC maturation, and induces a potent human in vitro primary immune response. J Immunol 165: 4710-4717, 2000. 
37. Bonehill A, Heirman C, Tuyaerts S, Michiels A, Breckpot K, Brasseur F, Zhang Y, van der Bruggen $\mathrm{P}$ and Thielemans $\mathrm{K}$ : Messenger RNA-electroporated dendritic cells presenting MAGE-A3 simultaneously in HLA class I and class II molecules. J Immunol 172: 6649-6657, 2004.

38. Zhao Y, Boczkowski D, Nair SK and Gilboa E: Inhibition of invariant chain expression in dendritic cells presenting endogenous antigens stimulates $\mathrm{CD}^{+} \mathrm{T}$-cell responses and tumor immunity. Blood 102: 4137-4142, 2003.

39. Sakaguchi S, Sakaguchi N, Asano M, Itoh M and Toda M: Immunologic self-tolerance maintained by activated $\mathrm{T}$ cells expressing IL-2 receptor alpha-chains (CD25). Breakdown of single mechanism of self-tolerance causes various autoimmune disease. J Immunol 155: 1151-1164, 1995.

40. Dieckmann D, Plottner H, Berchtold S, Berger T and Schuler G: Ex vivo isolation and characterization of CD4(+)CD25(+) T cells with regulatory properties from human blood. J Exp Med 193: 1303-1310, 2001.
41. Antony PA, Piccirillo CA, Akpinarli A, Finkelstein SE, Speiss PJ, Surman DR, Palmer DC, Chan CC, Klebanoff CA, Overwijk WW, Rosenberg SA and Restifo NP: $\mathrm{CD}^{+} \mathrm{T}$ cell immunity against a tumor/self-antigen is augmented by $\mathrm{CD}^{+} \mathrm{T}$ helper cells and hindered by naturally occurring $\mathrm{T}$ regulatory cells. J Immunol 174: 2591-2601, 2005.

42. Dudley ME, Wunderlich JR, Yang JC, Sherry RM, Topalian SL, Restifo NP, Royal RE, Kammula U, White DE, Mavroukakis SA, Rogers LJ, Gracia GJ, Jones SA, Mangiameli DP, Pelletier MM, Gea-Banacloche J, Robinson MR, Berman DM, Filie AC, Abati A and Rosenberg SA: Adoptive cell transfer therapy following non-myeloablative but lymphodepleting chemotherapy for the treatment of patients with refractory metastatic melanoma. J Clin Oncol 23: 2346-2357, 2005. 